\title{
Análise da relação principal- agente nos regimes próprios de Previdência Social: o caso do Agros
}

Caio César de Medeiros Costa; Alan Antunes Vieira Macabeu e Marco Aurélio Marques Ferreira

\section{Introdução}

A questão previdenciária no Brasil apresenta-se, desde o fim da década de 1980, como o cerne de inúmeras discussões que envolvem finanças públicas do País. Entre os vários motivos que elevaram a previdência a esse patamar, encontram-se os crescentes déficits, quer sejam os enfrentados pelo próprio Instituto Nacional do Seguro Social (INSS), criado a partir da edição da Lei $\mathrm{n}^{\circ} 8.029 / 1990$, quer sejam aqueles arcados pelos regimes previdenciários dos servidores públicos.

Ademais, há que se considerar tais fatos em associação a um histórico quadro de desigualdades e diferenças de direitos e regras. Fatos estes que fizeram com que esse tema ocupasse uma posição de destaque na agenda político-econômica do País (Zylberstajn, 2005).

De acordo com o INSS (2009), a previdência social é um seguro que garante a

renda do contribuinte e de sua família em casos de doença, acidente, gravidez, 
prisão, morte e velhice. Oferece vários benefícios que, juntos, garantem tranquilidade quanto ao presente e em relação ao futuro, assegurando um rendimento seguro.

A previdência se destaca como sendo uma das mais importantes políticas públicas do Brasil. Essa política é importante para o País, pois, se não houvesse, $34 \%$ dos idosos urbanos figurariam entre os 10\% mais pobres do País em 2008; no entanto, devido às transferências previdenciárias e assistenciais, os aposentados concentram-se nos 50\% superiores da escala de distribuição de renda, em que estão $79 \%$ dos beneficiários. No perímetro rural, a situação é semelhante: caso não houvesse a previdência rural, 39,4\% dos aposentados comporiam o grupo dos $10 \%$ mais pobres; no entanto, o pagamento regular de benefícios previdenciários na área rural faz com que quase a metade dos aposentados rurais $(47,7 \%)$ encontre-se entre o $5^{\circ}$ e o $7^{\circ}$ decil da distribuição de renda, ou seja, nos 30\% acima da metade da escala (INSS, 2009).

Entretanto, especificamente no caso brasileiro, a ocorrência dos mais variados problemas relacionados à questão da previdência, aliados à falta de transparência, contribuiu para que a confiança dos contribuintes no sistema de previdência social se tornasse cada dia menor.

Com isso, percebe-se a importância da emergência de mecanismos que garantam, ou facilitem, aos usuários dos planos de previdência o controle das finanças dos institutos responsáveis por lhes prover a aposentadoria. Nesse sentido, ações foram realizadas, destacando, entre elas, a criação do Cadastro Nacional de Informações Sociais (CNIS), que tem, entre outros objetivos, o de dar transparência às informações acerca da previdência, conforme disposto no sítio eletrônico da Dataprev (2010), vinculada ao Ministério da Previdência Social do governo federal.

A criação de mecanismos, como os citados anteriormente, contribui para diminuir o impacto negativo de erros de estratégia e gestão sobre a imagem da previdência social frente ao contribuinte. É salutar que assim ocorra, uma vez que, no País, vários são os institutos de seguridade social, conforme dados do Ministério da Previdência Social, publicados em seu Anuário Estatístico da Previdência Social (2008). Entre esses institutos, alguns apresentam situação diferenciada quando comparados à realidade da Previdência no País; em especial o Instituto UFV (Universidade Federal de Viçosa) de Seguridade Social (Agros), que se caracteriza como entidade de previdência privada fechada, e que se constitui sob a forma de sociedade civil pela Universidade Federal de Viçosa (UFV), cujo objetivo é suplementar as prestações asseguradas pela previdência oficial aos grupos familiares dos empregados dos patrocinadores, e promover o bem-estar social dos seus destinatários. $\mathrm{O}$ Instituto apresenta, de acordo com informações oriundas da própria instituição, uma situação financeira sólida (Agros, 2012).

Além da questão financeira, outras ações são realizadas com o intuito de proporcionar ao participante do Agros maior confiança no regime de previdência estabelecido via estatuto, a saber: o regime de previdência complementar. Destacamse, entre essas ações, a transparência em relação às informações, a proximidade entre instituto e participante, e demais ações que vão ao encontro dos princípios da governança e da accountability.

Tomando como base as considerações acima, identifica-se a importância de se verificar, sob a ótica do participante, os 
níveis de transparência de gestão administrativa do Agros e a confiança em relação ao regime de previdência do qual fazem parte. Ressalta-se a relevância da verificação quanto aos efeitos dessa transparência em relação à confiança do contribuinte nos aspectos relacionados principalmente à sua aposentadoria. Este estudo servirá ainda como um norteador das ações desses tipos de instituto e também do sistema de previdência social do País, dada a importância desses institutos e de sua contribuição para o sistema.

O presente artigo está estruturado em cinco seções. Além da seção introdutória, apresenta-se a seção com o referencial teórico; este, por sua vez, aborda a questão da previdência social no Brasil, Teoria da Agência e accountability e relação de confiança. A seção seguinte apresenta os procedimentos metodológicos que possibilitaram a realização da análise; na outra seção, encontram-se os resultados obtidos com a pesquisa; e, por fim, são feitas as considerações finais.

\section{Previdência social no Brasil}

De acordo com Silva (2009), a previdência social no Brasil, assim como na maior parte do mundo, teve início privativo, voluntário, mediante a formação dos primeiros planos mutualistas. A previdência social pode ser entendida como um seguro (seguridade social). Paga-se (hoje) para se obter (amanhã) um retorno em forma de benefícios financeiros. Com isso, garante-se a conservação do ordenamento, parcial ou integral, após o período laboral (Lima, 2006).

O marco inicial da legislação previdenciária no Brasil, de acordo com Beltrão et al. (2000), foi a Lei Eloy Chaves, editada em 1923. Conforme o disposto nessa legislação, a cobertura seria inicialmente restrita a uma parcela dos empregados urbanos de certas companhias, sendo paulatinamente estendida a outros grupos: empregadores, autônomos, empregados domésticos, trabalhadores rurais etc.

No plano constitucional, deixava-se o estágio da assistência pública para adentrar na era do seguro social. Não poderia ser diferente, uma vez que em todo o mundo, mesmo em sociedades industriais mais avançadas, não se tinha afastado a concep-

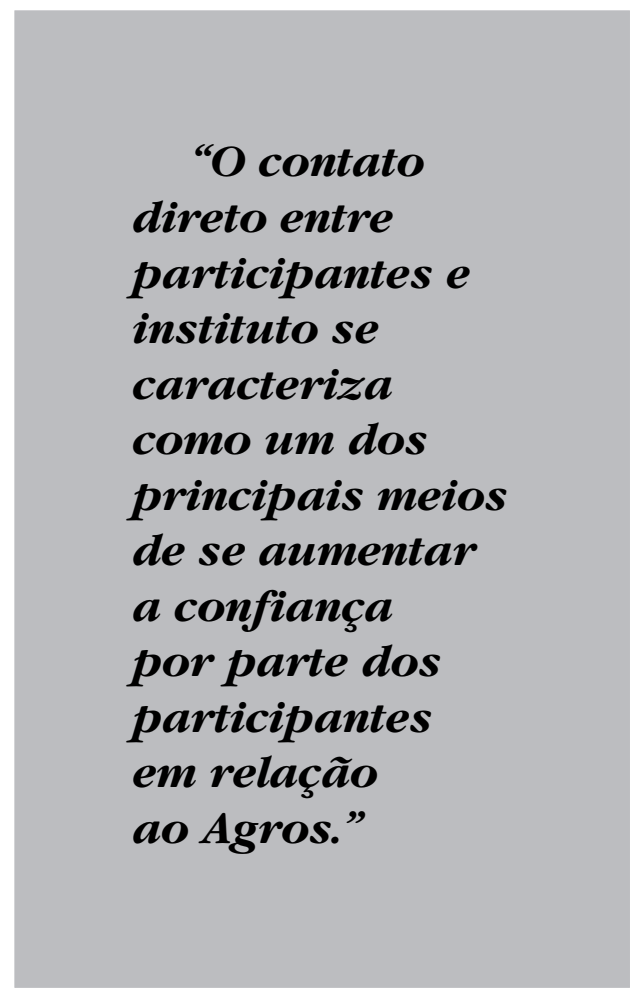

ção do seguro social. Nem mesmo o Social Security Act norte-americano, impulsionador da mudança de concepção do seguro social, havia sido concebido, já que data de 1935 (Pereira Júnior, 2005).

Foi com a promulgação da Constituição Federal de 1988, marco da objetivação democrática e social do Estado brasileiro, que se tratou de alargar o tratamento 
constitucional dado à previdência social, dispondo pela primeira vez do termo "seguridade social", como um conjunto de ações integradas envolvendo saúde, assistência e previdência social.

A seguridade social é uma técnica moderna de proteção social, que se busca implementar em prol da dignidade da pessoa humana. As suas diversas facetas, quais sejam, a assistência, a saúde e a previdência social, no sistema de seguridade social, deveriam atuar articulada e integradamente, mas percebe-se a existência de uma nítida separação no respectivo campo de atuação, extraída do próprio texto constitucional (Pereira JúnIor, 2005).

Há de se salientar, portanto, que, desde o início de suas atividades, vários foram os problemas referentes à questão previdenciária no Brasil, entre os quais se podem elencar desde os crescentes déficits à falta de equidade nos benefícios. Como consequência, tais dificuldades se apresentaram como estopim para reformas previdenciárias realizadas, as quais culminaram na criação de mecanismos, no intuito de romper com essas mazelas relacionadas à previdência e apresentar a resposta social ansiada.

Segundo Lima (2006), as reformas da previdência começaram a ocorrer no Brasil em dezembro de 1998, por meio da Emenda Constitucional $\mathrm{n}^{\circ} 20$, a qual visava a romper com a cultura patrimonialista vigente e buscava estabelecer um novo modelo a ser implementado na previdência social; a partir de então, a aposentadoria seria compreendida como o resultado de uma contrapartida contributiva, a qual deveria ser calculada com base em preceitos que assegurassem o equilíbrio financeiro e atuarial do regime: reforma seguida de mais duas, a saber, nos anos de 2003, a partir da edição da Emenda Constitucional $n^{\circ} 41$, e, em 2005, com a edição da Emenda no 47.
Além das reformas supracitadas, podem-se enumerar outros mecanismos criados de modo a corrigir as questões relacionadas ao tema previdenciário. Entre estes, destacam-se os planos de previdência complementar que foram criados de modo a garantir o rendimento do trabalhador na aposentadoria, diminuindo a defasagem entre o valor recebido na ativa e o valor dos proventos oriundos da previdência.

Nesse sentido, alguns planos de previdência complementar se caracterizam como fundos de pensão operados pelas entidades fechadas de previdência complementar, juridicamente sem fins lucrativos, criados a partir do vínculo entre empresas e trabalhadores. Tal sistema conta com mais de 2 milhões de participantes ativos e assistidos, vinculados a fundos de pensão, detentores de uma poupança previdenciária de aproximadamente $\mathrm{R} \$ 200$ bilhões. Trata-se ainda de um número pequeno de pessoas e de recursos, se levado em conta o potencial existente (BrasIL, 2003).

Entre as várias vantagens relacionadas aos fundos de pensão operados por entidades fechadas de previdência complementar, ligadas a classes profissionais específicas ou a trabalhadores ligados a uma mesma organização, encontra-se:

O aproveitamento da identidade de grupo (vínculo associativo) para uma finalidade previdenciária tem inúmeras vantagens, entre elas o estreitamento da relação entre a direção dessas entidades e seus associados, custos de administração menores, incentivos fiscais e maior rentabilidade - já que, nos fundos de pensão fechados, todo o ganho obtido com as aplicações das contribuições é revertido exclusivamente aos participantes do plano previdenciário (BRASIL, 2003, p.7). 
Pelo exposto, nota-se como a questão previdenciária, principalmente no Brasil, ganha vulto à medida que as disparidades aumentam e, com estas, surgem novas medidas com vistas a saná-las. Não há de se perder, entretanto, o foco primordial, que se encontra na relação existente entre aquele que necessita buscar o auxílio previdenciário, e aquele que presta esse serviço.

\section{Teoria da Agência}

A Teoria da Agência procura entender e explicar os fatos e conflitos que possam advir da relação entre dois, ou mais, indivíduos. Conforme Hendriksen \& Breda (1999), "um desses dois indivíduos é um agente do outro, chamado de principal daí o nome de teoria de agency. O agente compromete-se a realizar certas tarefas para o principal e este se compromete a remunerar o agente".

Supõe-se, então, que o agente tome decisões que visem aos interesses do principal; no entanto, de acordo com Eisenhardt (1989), principal e agente estão vinculados em um comportamento coorporativo, mas possuem diferentes objetivos e diferentes atitudes com relação ao risco do negócio.

No mesmo sentido, caminhando pela Teoria dos Contratos, Jensen e Meckling (1976) definem uma relação de agência como: "um contrato pelo qual uma ou mais pessoas contrata outra pessoa, ou outras, para executar algum serviço em seu favor, e que envolva delegar, ao agente, alguma autoridade de tomada de decisão".

Cumpre ressaltar que a Teoria de Agência, ao salientar a relação entre principal e agente, não se refere unicamente à relação entre proprietário/acionista e administradores/gestores. Logo, tal relação pode ser estabelecida entre diversos tipos de principal e agente.

A princípio, toda e qualquer relação de agência pode sugerir a busca de eficiência, já que o principal, uma vez que não dispõe de experiência, tempo, competência, capacitação, repassa ao agente a tarefa de gerenciamento de recursos e execução de atividades. No entanto, conforme ressaltam Jensen e Meckling (1976), "se ambas as partes do relacionamento são maximizadores de utilidade, existe boa razão para acreditar que o agente não agirá sempre pelos melhores interesses do principal”.

A Teoria da Agência focaliza relações contratuais entre indivíduos. Ademais, busca compreender a natureza dos conflitos que possam advir da relação de agenciamento, quando os interesses, entre principal e agente, divergirem.

Tomando por base o Regime Próprio de Previdência Social (RPPS), as relações nele estabelecidas, entre gestores e servidores - estes últimos chamados de contribuintes -, podem gerar uma gama de conflitos, entre os quais podem ser elencados divergências na definição de valores de taxa, ou de portfólio de investimento, etc. Necessita-se, portanto, procurar mecanismos que visem a reduzir essa insegurança, ou seja, que minimizem, tanto quanto possível, essas áreas de conflito.

Ao se apropriar dos conceitos elencados pela Teoria da Agência e aplicandoos ao mundo dos RPPS, pode-se classificar, então, o servidor como principal, e o gestor do RPPS, como agente. Nesse caso, o servidor, mesmo que de forma compulsória, confia a outrem a realização de tarefa de seu interesse, a saber, a administração dos recursos garantidores de sua aposentadoria futura, o que confere ao gestor, necessariamente, em alguma medida, poder de decisão. 
O ideal, no que tange ao sistema previdenciário, seria que o principal tivesse as mínimas condições de fiscalizar, e, consequentemente, cobrar ações que pudessem garantir-lhe a aposentadoria.

Tal cenário seria possível a partir da conscientização, por parte do agente, de que a informação precisa ser popularizada, ou seja, é necessário conferir transparência às ações; ou também, como outra medida, com o simples cumprimento da legislação vigente, que, por si só, elenca mecanismos que, ao menos no plano das ideias, deveriam garantir o acesso à informação por parte dos interessados. É interessante notar que sob essa perspectiva se demonstra, talvez, o principal conflito na relação contratual principal/agente no mundo dos RPPS.

Segundo Byrd et al. (1998), a qualidade das decisões/escolhas dos agentes não depende somente de suas habilidades, mas também dos incentivos que lhes são oferecidos. Portanto, quando um agente está disposto a maximizar a sua função/utilidade, e não a do principal, identifica-se um conflito de agência.

O problema da agência é um aspecto de extrema relevância na relação entre agente e principal. De acordo com o entendimento de Hatch (1997), o problema de agência, ou conflito da agência, envolve o risco de o agente agir de acordo com seus próprios interesses, em vez de agir em conformidade com os interesses do principal. A fim de evitar os problemas decorrentes dessa divergência de interesses, a solução é a realização de contratos, cujo objetivo é dar conformidade aos interesses bilaterais.

$\mathrm{Na}$ mesma linha de raciocínio, conforme Eisenhardt (1985), a capacidade dos principais de saber se os agentes estão ou não agindo de acordo com seus interesses, depende das informações disponíveis, que podem ser conseguidas de forma direta, por meio do monitoramento das ações dos agentes, ou mesmo indiretamente, pelo acompanhamento dos resultados.

No intuito de garantir os interesses do principal, faz-se necessária a criação de mecanismos que reduzam a possibilidade de os agentes agirem de maneira diversa. Nesse processo incorrem custos, os quais são denominados, segundo Clegg, Hardy e Nordy (1996), custos de agência. Devese ressaltar que os custos totais de agência se constituem em: o montante gasto no monitoramento pelo principal, os custos da dependência do agente e a perda residual arcada pelo principal.

Arrow (1985) identificou duas fontes principais de problemas de agência: o moral hazard, ou risco moral, que está relacionado com acobertar ações, e a seleção adversa, relacionada a acobertar informações. O risco moral envolve situações em que as ações dos agentes não são de conhecimento do principal ou são muito onerosas para serem observadas. Já a seleção adversa representa o fato de os agentes possuírem informações desconhecidas por parte do principal, ou cujos custos de obtenção são elevados.

Os problemas de agência são resolvidos normalmente de duas maneiras: monitoramento e penalização. Para Clegg, Hardy e Nord (1996), o monitoramento envolve a observação do desempenho dos agentes, pois, de acordo com Holmstrom (1979), quanto mais de autonomia e independência o agente goza e quanto maior o conhecimento especializado necessário na execução da tarefa, mais significativo é o perigo da falta de controle. A penalização trata-se da punição de um comportamento não desejado dos agentes. Em outras palavras, aborda-se a temática dos mecanismos de controle. 
Accountability e os sistemas de previdência social

A accountability, conforme Tiburcio Silva et al. (2000), dada a complexidade do seu conceito, seria o dever de prestar contas. Apresenta-se como um dos norteadores da governança corporativa. No entendimento de Kluvers (2003), sem uma accountability adequada, o gerenciamento dos recursos pode, na melhor das hipóteses, ser ineficaz e incompetente e, na pior das hipóteses, corrupto.

No caminho do entendimento em que se insere a accountability, Nakagawa (2003) busca elucidar:

Sob a ótica da teoria dos contratos e como consequência das relações sociais, políticas e econômicas que ocorrem em qualquer sociedade, verifica-se, de um lado, que há sempre uma delegação de poder (autoridade), e de outro, como contrapartida, a geração de responsabilidades, formando assim uma grande cadeia de accountability (Nakagawa 2003, p.17).

Nesse sentido, então, accountability corresponderia à obrigação de executar algo e decorreria da autoridade delegada. Mosher (1968) afirma que a accountability é sinônimo de responsabilidade objetiva, ou seja, trata-se da responsabilidade de uma pessoa ou organização perante a outra, fora de si mesma. Tal responsabilidade traz consequências, desde prêmios pelo seu cumprimento, até castigos pelo oposto.

Daí percebe-se que a necessidade desse mecanismo de controle decorreria dos conflitos de interesses entre as partes envolvidas na relação de contrato, sendo esta formal ou não.
Assim, passa a ser de vital importância a busca por minimização de conflitos, sendo a prestação de contas um desses mecanismos, uma vez que se apresenta como instrumento de controle que visa a permitir a popularização das informações a todos os interessados.

$\mathrm{O}$ ato de prestar contas deveria ser atitude de qualquer gestão, uma vez que, a partir daí, haveria a possibilidade de obterem-se parâmetros de desempenho. Entre-

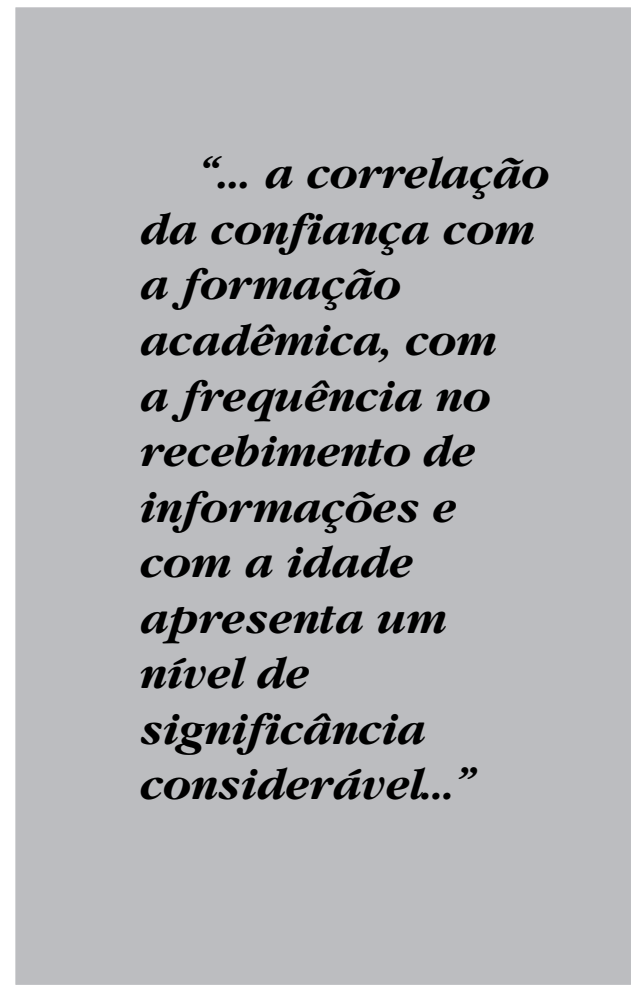

tanto, na vida quotidiana da administração pública, não parece ser a tônica, como se verifica a seguir:

Os problemas mais contundentemente criticados são, entre outros, a lentidão no processo decisório (burocracia excessiva), uma demanda crescente por necessidade de financiamento (tributação elevada) e 
a ausência de um processo de avaliação do desempenho do gestor público que seja objetivo e eficaz, sugerindo quase que uma tendência da gestão pública para o desperdício. (RIBEIRO FILHO, 1999, p. 7)

Desperdício que nos RPPS pode desembocar na carência de recursos necessários ao pagamento do passivo atuarial dos fundos. Logo, a utilização de mecanismos de controle, como a prestação de contas, com fins de tornar públicos atos praticados, se apresenta como forma de minimizar os efeitos de escassez futura.

\section{A relação de confiança}

A partir dos conceitos já expostos, é possível delinear uma definição ainda não mencionada, mas de vital importância, quer seja para o caso específico dos regimes próprios de previdência social, quer seja no desenrolar das atividades da administração pública em geral: a confiança.

Enumeram-se diferentes abordagens acerca do tema, tais como: confiança e desenvolvimento socioeconômico (Fukuyama, 1996), confiança e sistemas sociais (Luhmann, 1979). Arrow (1974) aponta que, a partir do ponto de vista econômico, confiança é reconhecidamente considerada como um lubrificante para a troca econômica e um mecanismo eficiente para governar as transações econômicas nas sociedades. De modo mais específico, em estudos da gerência e da organização, a literatura, ao tratar da confiança, aborda-a enquanto fator inter e/ou intraorganizacional (Tzafrir E Harel, 2002). E tal é o contexto utilizado pelo presente estudo, qual seja, a confiança intraorganizacional e sua influência nas relações pessoas-organização.
No entendimento de Tzafrir e Harel (2002), é possível identificar três pontos críticos na análise da confiança, a saber: a) questões associadas à vulnerabilidade/ risco; b) o problema da reciprocidade; c) a dinâmica das expectativas.

No tocante às questões associadas à vulnerabilidade/risco, a definição de confiança mais comumente apresentada está associada à disposição de alguém a ser vulnerável em relação à outra pessoa, cujos comportamentos não se pode controlar, ou, ainda, com base na crença de que o outro é competente, franco e responsável (Mishra, 1996). Em outras palavras, os comportamentos de confiança conferem segurança a organizações e pessoas, a fim de que estas tenham minimizado seu receio em assumir riscos. Desse modo, a inclinação a arriscar surge na literatura como uma das poucas características que pode ser comum a todas as situações de confiança. Por seu turno, o risco seria, então, a condição essencial em conceituações de confiança, sejam elas de caráter psicológico, social ou econômico. Pode-se verificar, então, que a assunção de riscos numa relação reforça o sentido de confiança.

No que diz respeito à questão da reciprocidade, esta está ligada ao fato de se observar que um cenário de interações positivas tende a elevar o nível de confiança entre as partes. Quer dizer, essas interações positivas mútuas entre os atores envolvidos acarretam, portanto, a constituição de perspectivas em longo prazo (Tzafrir e Harel, 2002). As normas de reciprocidade têm grande influência sobre a confiança e constituem-se em característica que geralmente acompanha as relações baseadas na confiança.

Quanto à dinâmica da expectativa, considera-se que a confiança traz embutida uma expectativa positiva. Tal expectativa do 
resultado da outra parte forma um elemento central na definição de confiança. A disposição para assumir riscos baseia-se na expectativa de que a outra parte cumprirá uma determinada ação importante para aquele que confia. A violação dessas expectativas, portanto, resultaria em consequências negativas para os envolvidos (TZAFrIR e Harel, 2002).

\section{Metodologia}

Para subsidiar este estudo, foram utilizados métodos quantitativos, de modo a esclarecer as relações entre o Instituto UFV de seguridade social (Agros) e os seus participantes, sob as diferentes perspectivas abordadas pelo referencial teórico.

\section{Fonte de dados}

A população-alvo deste estudo foi estabelecida de acordo com Hair et al. (2005), que a define como o grupo completo de objetos ou elementos que possuem informações relevantes. Dessa maneira, a população-alvo deste estudo foi constituída pelos servidores ativos da Universidade Federal de Viçosa e da Fundação Arthur Bernardes, optantes pela previdência complementar do Agros. Os questionários foram aplicados entre os dias 30 de junho de 2010 e 07 de julho de 2010. A população definida segue os critérios estabelecidos.

Segundo dados do relatório anual de informações do Agros (2009), o número de participantes ativos dos planos de previdência do instituto contabiliza um total de 4,4 mil participantes.

De modo a selecionar a amostra que compõe o estudo, foi realizado o cálculo estatístico da amostra aleatória, utilizado em estudos em que a população-alvo é considerada finita. O cálculo é feito tomando como base a equação 1 , apresentada abaixo:

$$
\text { (1) } \eta=\frac{\sigma^{2} \cdot p \cdot q \cdot N}{e^{2} \cdot(N-1)+\sigma^{2} \cdot p \cdot q}
$$

$\mathrm{Na}$ equação acima, o $\eta$ representa o tamanho da amostra aleatória, é igual ao nível de significância (sigma), o valor de p demonstra a probabilidade de manifestação do evento, o q apresenta o valor complementar a p, ou seja, 1-p. Por fim, o valor de $N$ traz o tamanho da população de indivíduos e o valor é o erro máximo tolerado no estudo. Para a realização dessa análise, os valores apurados foram: $=1,645$; $q=0,5 ; p=0,5 ; N=4.400$ e o valor de $=0,05$. Tomando como base esses valores, apurou-se o tamanho da amostra aleatória que, para este estudo, foi de 254 indivíduos.

\section{Elaboração do questionário: formulação dos constructos}

Os questionários, para obtenção dos dados utilizados para a realização deste estudo, foram utilizados tomando como base as teorias acerca da temática abordada. De acordo com Hair et al., (2005) e Malhotra (2001), o conjunto de teorias a respeito do tema estudado é a principal fonte de subsídios para a construção de questionários consistentes. Para a realização deste estudo, os questionários elaborados basearam-se em Lima (2006).

De acordo com Hair et al. (2005), a primeira etapa para a elaboração do questionário é a definição dos conceitos ou construtos a serem pesquisados. Deve-se assegurar que não haja ambiguidade em sua interpretação.

De modo a possibilitar essa análise, foram criados constructos relacionados aos temas abordados neste estudo, ou seja, 
relacionados à confiança e à transparência. Tomando como base Hair et al. (2005), um constructo é um conceito ou uma ideia genérica constituída pela combinação de uma série de características semelhantes, que coletivamente definem e tornam a mensuração do conceito possível. Os agrupamentos das variáveis pesquisadas para a realização deste estudo formam os constructos que possibilitam a realização da análise objetivada pela pesquisa. A escolha das variáveis que compuseram o constructo se baseou na teoria referente aos temas abordados, tomando como base principal os estudos de Lima (2006).

Os constructos utilizados para avaliar a relação entre os participantes e o Agros estão apresentados no Quadro 1.
O Quadro 1 apresenta as variáveis utilizadas para a formação de cada constructo. A realização desse processo de formação dos constructos visa a facilitar o entendimento acerca de determinados conceitos, cujo entendimento somente é possível por meio do agrupamento de certas variáveis.

\section{Construção e validação da escala}

De modo a mensurar as variáveis, optou-se pela escala Likert. Segundo Güthner (2003), a escala Likert é uma mensuração mais utilizada nas ciências sociais, especialmente em levantamentos de atitudes, opiniões e avaliações. De acordo com Malhotra (2001), Likert é uma

\section{Quadro 1: Constructos utilizados na análise}

\begin{tabular}{|c|c|}
\hline Constructo & Variáveis \\
\hline \multirow{4}{*}{ Transparência } & $\begin{array}{l}\text { Em relação ao nível de confiança e segurança } \\
\text { transmitida pelas informaçōes relativas ao regime } \\
\text { previdenciário do qual você participa. }\end{array}$ \\
\hline & $\begin{array}{l}\text { Em relação à obtenção (acesso) de informações } \\
\text { relativas ao seu plano de previdência. }\end{array}$ \\
\hline & $\begin{array}{l}\text { A prestação de contas é um meio de os } \\
\text { interessados fiscalizarem e controlarem os atos } \\
\text { dos administradores. }\end{array}$ \\
\hline & $\begin{array}{l}\text { Em relação à compreensão das informaçòes } \\
\text { relativas ao regime previdenciário do qual você } \\
\text { participa. }\end{array}$ \\
\hline \multirow{3}{*}{ Confiança } & $\begin{array}{l}\text { Com relação à preocupação com sua situaçào } \\
\text { financeira após se aposentar. }\end{array}$ \\
\hline & $\begin{array}{l}\text { Com relação à contribuiçao previdenciária, você } \\
\text { acredita que o valor descontado do seu salário } \\
\text { pode ser considerado. }\end{array}$ \\
\hline & $\begin{array}{l}\text { Você acredita que o regime de previdência } \\
\text { complementar, do qual você faz parte, é um } \\
\text { sistema seguro, e, por isso, está seguro(a), pois } \\
\text { sabe que receberá sua aposentadoria quando } \\
\text { chegar a hora certa. }\end{array}$ \\
\hline
\end{tabular}

Fonte: Elaborado pelos autores 
escala de medida com cinco ou sete categorias de respostas, que vão de "discordo totalmente" a "concordo totalmente", e que exige que os participantes indiquem seu grau de concordância ou de discordância com cada uma de uma série de afirmações relacionadas com o objeto de estudo.

Optou-se por utilizar uma escala de 7 pontos, de modo a permitir aos respondentes maior possibilidade de respostas. Utilizou-se uma escala equilibrada, para que o número de categorias favoráveis e desfavoráveis seja o mesmo e para não influenciar os respondentes nas suas avaliações. Foi escolhido um número ímpar de categorias, a fim de possibilitar que o respondente adotasse uma postura neutra em relação à afirmação.

A escala utilizada pode ser considerada forçada, pois as categorias apresentadas não permitiam ao respondente se abster da resposta. Caso o mesmo apresentasse dúvidas, poderia optar pela neutralidade.

\section{Transformação dos dados}

De modo a possibilitar este estudo, foi realizada a transformação dos dados. Hair et al. (2005) apontam que a transformação dos dados pode ser um importante processo de modificação dos dados originais para um novo formato, que seja mais adequado para a realização de um procedimento estatístico.

O procedimento utilizado foi a combinação das médias das variáveis escolhidas pelos respondentes em cada questão relacionada a determinado conceito, ou seja, ao constructo. Esse procedimento possibilitou mensurar qual a percepção do participante do Agros sobre cada um dos dois constructos estudados.

\section{Análise de correlação}

De modo a avaliar a relação entre as variáveis utilizadas neste estudo, foram realizados testes estatísticos, testes de correlação.

A correlação indica se existe ou não inter-relacionamento entre variáveis. No caso deste artigo, buscou-se verificar se existe inter-relação entre o nível de confiança dos participantes do Agros, as

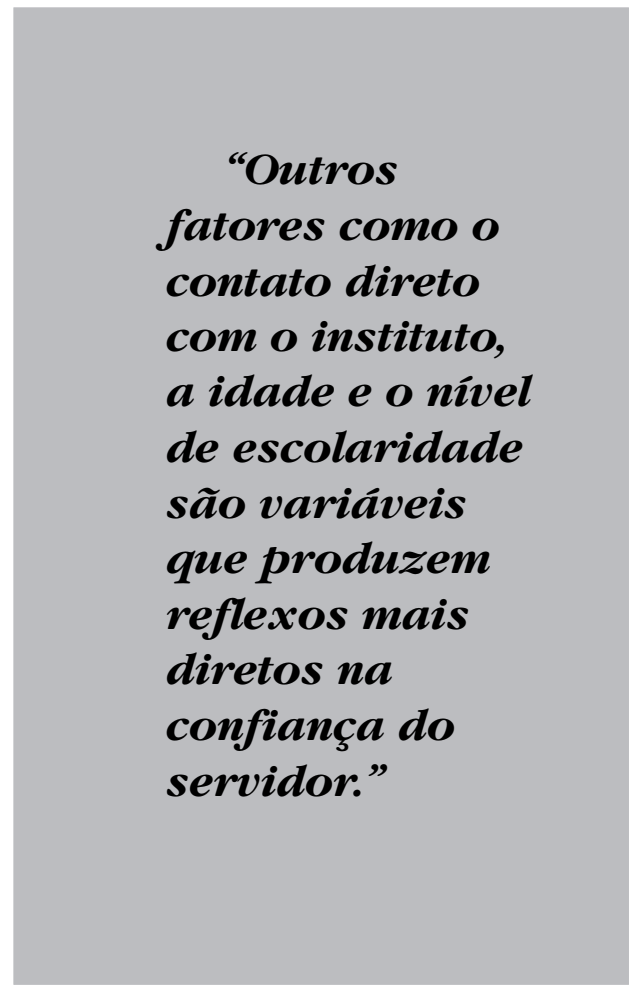

características desses usuários e o contato instituto-participante.

\section{Teste qui-quadrado}

O teste qui-quadrado é o teste estatístico mais antigo e um dos mais utilizados em pesquisa social. Segundo Barbetta (2008), é um método que permite testar a 
significância da associação entre duas variáveis, como também comparar duas ou mais amostras quando os resultados da variável-resposta estão dispostos em categoria.

O teste qui-quadrado se destina, portanto, a avaliar a associação existente entre variáveis e se baseia na comparação das proporções, ou seja, nas possíveis divergências entre as frequências observadas e esperadas para um evento específico (Beiguelman, 1996).

O teste de ajustamento do qui-quadrado é de fácil construção e se baseia na comparação da distribuição dos dados da amostra (frequências observadas) com a distribuição teórica, à qual a amostra se supõe pertencer (UFPE, 2010).

Para a realização do teste qui-quadrado, considera-se uma amostra aleatória de $\mathrm{n}$ elementos, extraída de uma população com distribuição desconhecida, sobre os quais se observa uma característica (qualitativa ou quantitativa) (HenRIQUES e ReIs, 2010).

Para que o teste seja realizado, é necessário que:

- os grupos sejam independentes;

- os itens de cada grupo sejam selecionados aleatoriamente;

- as observações sejam por frequências ou contagens;

- cada observação pertença a somente uma categoria e que a amostra seja relativamente grande (com pelo menos cinco observações em cada célula e, no caso de poucos grupos, pelo menos 10) (Beiguelman,1996).

Para a realização das análises deste estudo, o teste qui-quadrado é de extrema importância, pois demonstra a independência ou não dos grupos ou estratos relacionados a cada constructo, permitindo verificar a correlação entre esses grupos. No âmbito deste estudo, testaram-se as hipóteses de independência das variáveis
( $\mathrm{H}_{0}$ ou hipótese nula) e de dependência das mesmas ( $\mathrm{H}_{a}$ ou hipótese alternativa).

Levando-se em conta as características dos dados utilizados na realização desta pesquisa e o alto nível de confiabilidade do teste qui-quadrado, optou-se pela realização do mesmo por meio do software SPSS $®$ 15- Statistical Package for the Social Sciences - em versão licenciada.

\section{Análise dos resultados}

Com o objetivo de analisar a relação de confiança entre os participantes e o Agros, sob a perspectiva daqueles, o presente artigo buscou conhecer a relação entre as características dos participantes, as ações do instituto em relação à transparência e o nível de confiança entre o Agros e os seus participantes.

De modo a favorecer as análises, demonstra-se de extrema importância a caracterização do objeto estudado. Segundo informações colhidas junto ao próprio Instituto UFV de Seguridade Social (Agros), este se constitui em uma entidade fechada de previdência privada, sob a forma de sociedade civil, sendo vinculado à Universidade Federal de Viçosa. Possui a finalidade de suplantar as prestações asseguradas pela previdência oficial aos grupos familiares dos empregados dos patrocinadores (a própria UFV e o próprio Agros), e promover o bem-estar social dos seus destinatários.

O Instituto foi criado em 8 de maio de 1980, data da portaria $n^{\circ} 2119$, assinada pelo então Ministro da Previdência e Assistência Social Jair Soares.

Com o propósito de avaliar a relação entre agente (Agros) e principal (Participante), baseada na descrição da Teoria da Agência, realizou-se o cruzamento das respostas dos questionários que envolviam questões vinculadas: a) às características 
inerentes aos participantes, b) às ações do instituto de previdência complementar, e c) ao nível de confiança estabelecido nessa relação.

De modo a verificar os níveis de confiança dos participantes em relação ao Agros, buscou-se visualizar, por meio de uma correlação entre as respostas dadas pelos contribuintes, as questões do questionário e as características inerentes aos participantes.

Nesse sentido, os resultados obtidos são demonstrados nos gráficos aqui apresentados. Cumpre ressaltar que as análises ora descritas são baseadas nas respostas obtidas do grupo dos participantes que declararam ter a) maior idade, b) mais tempo de serviço, c) receber mais informações do instituto de previdência complementar. Sendo assim, o artigo baseou-se na literatura que descreve esses grupos como os mais propensos a demonstrarem maior confiança nos institutos de previdência.

Há de se salientar que foram realizadas as análises para todos os demais grupos de participantes; entretanto, tais percepções, por ora, não colaborariam para a solução do problema de pesquisa.

A seguir, apresentam-se os resultados do estudo, sob a forma de gráficos, para os grupos considerados na relação principal/agente, em se tratando dos regimes próprios de previdência social.

No Gráfico 1, percebe-se a forma como o tempo de serviço influencia a confiança do servidor. Nota-se que mais da metade dos respondentes com mais de 13 anos de serviço confia no instituto de previdência complementar ao qual está vinculado, corroborando o entendimento da literatura que aponta para a formação da relação principal/agente e a confiança em que se baseia tal relação.
No Gráfico 2, verifica-se que o recebimento de informações do instituto de previdência também acompanha as expectativas; em outras palavras, mais de $50 \%$ dos respondentes, que afirmaram receber informações mensalmente, confiam de maneira satisfatória em seu agente. $\mathrm{O}$ contato direto entre participantes e instituto se caracteriza como um dos principais meios de se aumentar a confiança por parte dos participantes em relação ao Agros. Destacase, assim, o envio mensal do informativo do Agros, que, além das várias informações acerca do instituto, apresenta questões ligadas ao cotidiano dos participantes, desde dicas de saúde a questões relacionadas com educação financeira. Nesse sentido, essas ações podem ser consideradas como comportamentos de confiança que conferem segurança a organizações e a pessoas, a fim de que estas tenham minimizado seu receio em assumir riscos.

O Gráfico 3 demonstra a confiança apresentada pelos servidores que possuem mais de 53 anos.

Percebe-se, mais uma vez, que mais da metade dos respondentes confia no instituto, demonstrando que os servidores que se aproximam da idade apta à aposentadoria confiam no plano de previdência do Agros, porém em um baixo nível; pois, como demonstrado pelo estudo, 47,6\% dos participantes têm baixa confiança no instituto, o que demonstra a necessidade de que este realize ações que visem a ampliar a confiança dos participantes, ao se aproximar a idade de aposentadoria dos servidores da Universidade Federal de Viçosa.

O resultado deste gráfico vai contra as análises realizadas no Gráfico 1, que aponta que os usuários com mais de 13 anos de serviço confiam em maior nível no Agros. Porém, essa divergência pode ocorrer devido à diferença entre intervalos de 


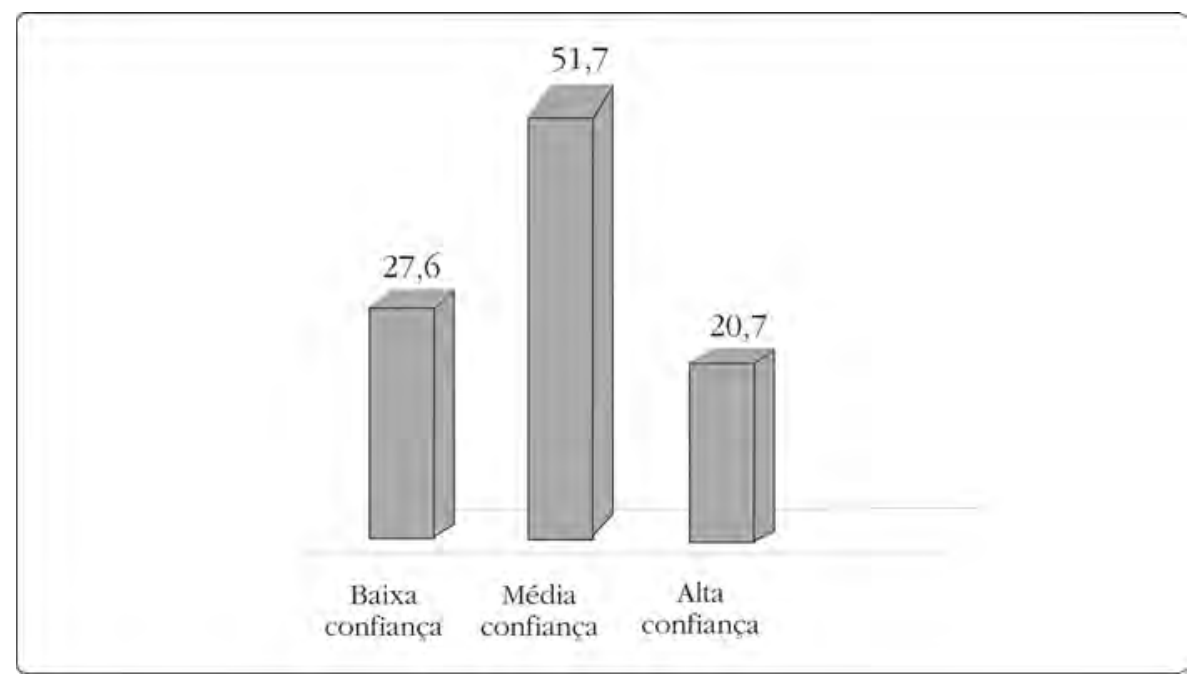

Fonte: Elaborado pelos autores.

Gráfico 1: Relação da confiança com o tempo de serviço - servidores com mais de 13 anos de serviço

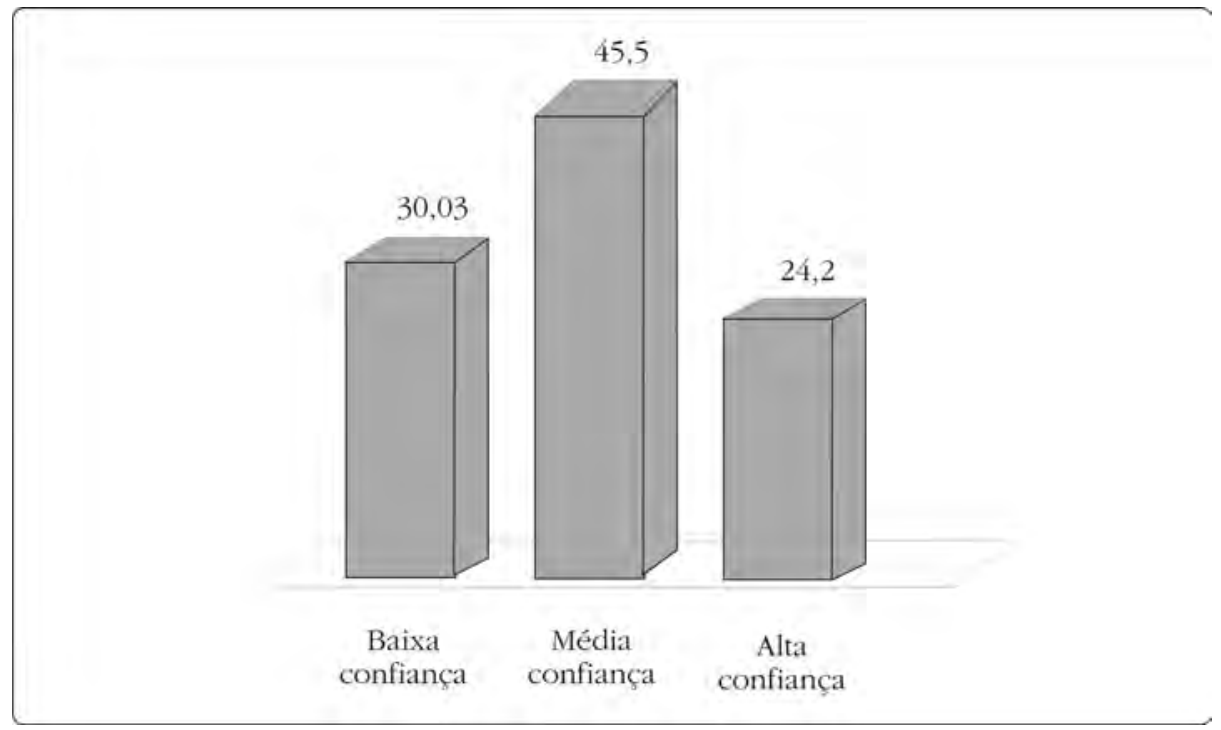

Fonte: Elaborado pelos autores.

Gráfico 2: Relação da confiança com o recebimento de informações - servidores que recebem informações mensalmente 


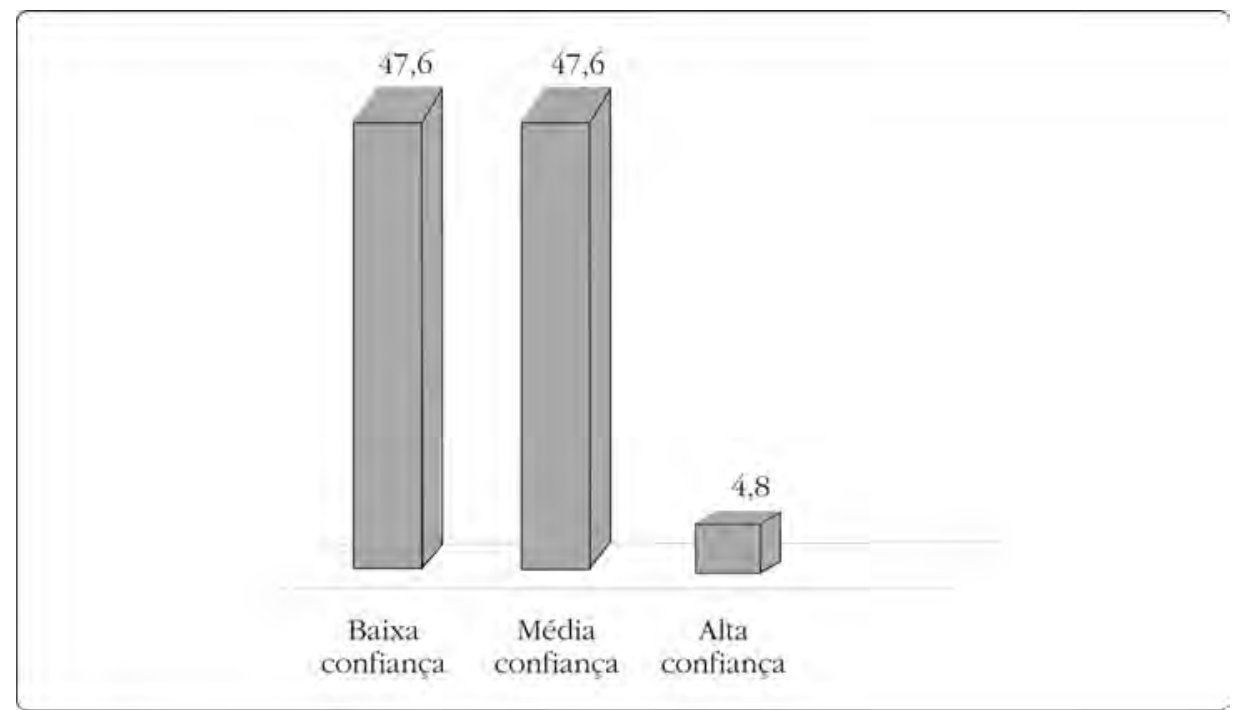

Fonte: Elaborado pelos autores.

Gráfico 3: Relação da confiança com a idade - servidores com idade acima de 53 anos

período ocorridos em cada análise e, principalmente, pelo fato de a idade de 53 anos ser muito próxima da idade na qual a maior parte dos servidores se encontra apto à aposentadoria.

O teste qui-quadrado foi realizado com o intuito de conhecer o nível de independência das variáveis; nesse sentido, analisouse o nível de significância da correlação entre o constructo confiança e as demais variáveis.

A Tabela 1 demonstra que a correlação da confiança com a formação acadêmica, com a frequência no recebimento de informações e com a idade apresenta um nível de significância considerável, o que possibilita, por meio do teste qui-quadrado, rejeitar a hipótese $\mathrm{H}_{0}$, e, portanto, não rejeitar a hipótese alternativa de dependência entre as variáveis, a um nível de significância de $10 \%$.

Nesse sentido, o teste aponta que essas variáveis são associadas em relação à variável confiança. As demais variáveis, como transparência, tempo de experiência no serviço público federal, frequência com que busca as informações e fonte em que

Tabela 1: Resultados do teste qui-quadrado: relação entre o nível de confiança e as demais variáveis

\begin{tabular}{|c|c|c|c|c|c|c|c|}
\hline & Transparência & $\begin{array}{c}\text { Tempo de } \\
\text { experiência } \\
\text { no serviço } \\
\text { público }\end{array}$ & $\begin{array}{l}\text { Formaçio } \\
\text { académica }\end{array}$ & $\begin{array}{c}\text { Frequência } \\
\text { no recebimento } \\
\text { de informaçōes }\end{array}$ & $\begin{array}{c}\text { Frequência na } \\
\text { busca por } \\
\text { informacòes }\end{array}$ & $\begin{array}{c}\text { Fonte de } \\
\text { informaçes }\end{array}$ & Idade \\
\hline \multicolumn{8}{|l|}{ Confiança } \\
\hline Nivel de significància & 0.673 & 0,533 & 0.061 & 0,012 & 0,353 & 0.669 & 0,075 \\
\hline
\end{tabular}

Fonte: Elaborada pelos autores. 
essa informação é buscada, apresentaram um nível de significância que permite a não rejeição de $\mathrm{H}_{0}$ que aponta que as variáveis são independentes.

Por meio das análises, torna-se factível afirmarmos que as variáveis que se relacionam com a confiança, com exceção da frequência no recebimento de informações, são variáveis sobre as quais o instituto não tem qualquer poder de interferência. Nesse sentido, entre as possíveis ações avaliadas por este estudo, pode-se afirmar que o Agros deve ter um contato constante com os seus participantes, dando-lhes sempre ciência das realizações do instituto.

Isso diminui a sensação de vulnerabilidade/risco, pois permite ao participante aumentar a crença de que o outro (Agros) é competente, franco e responsável (Mishra, 1996). E, portanto, diminui os chamados conflitos da agência por meio de ações de baixo custo e de alto retorno para o instituto.

\section{Considerações finais}

Este trabalho permitiu analisar, sob a ótica do participante do Agros, os níveis de transparência da gestão administrativa do instituto e a confiança em relação ao regime de previdência do qual faz parte.

Além disso, foi essencial a verificação quanto aos efeitos dessa transparência em relação à confiança do contribuinte nos aspectos relacionados principalmente à sua aposentadoria.

Deve-se ressaltar que, para o grupo analisado, ou seja, aqueles que se declararam pertencentes à faixa de maior idade, ou que possuíam mais tempo de serviço, ou ainda aqueles que recebiam mais informações do instituto de previdência complementar, apresentaram-se respostas em concordância com o referencial teórico, ou seja, demonstrou-se nível maior de confiança no instituto de previdência a que estavam vinculados.

Tomando como base o constructo criado para a realização deste estudo, o qual foi chamado de transparência, percebe-se que os níveis de confiança não dependem da transparência das informações acerca da previdência. Outros fatores como o contato direto com o instituto, a idade e o nível de escolaridade são variáveis que produzem reflexos mais diretos na confiança do servidor.

Levando-se em conta os três pontos críticos da confiança, percebe-se que as variáveis que demonstraram correlação com a confiança possibilitam a criação de um nível de confiança baseado na dinâmica da expectativa, apontada por Tzafrir e Harel como elemento central na definição de confiança. A disposição para assumir riscos é baseada na expectativa de que a outra parte cumprirá uma determinada ação importante para aquele que confia. A violação dessas expectativas, portanto, resultaria em consequências negativas para os envolvidos.

O aumento dos níveis de confiança possibilita a diminuição dos conflitos da agência inerentes ao relacionamento entre agente e principal.

Cabe ressaltar que a análise realizada leva em conta as variáveis que formaram o constructo, conforme demonstrado na metodologia. Não necessariamente análises utilizando outras variáveis relacionadas aos temas abordados trariam resultados semelhantes.

Outras análises podem ser realizadas com os dados obtidos por este estudo, como a percepção da confiança dos novos entrantes no Setor Público, ou seja, aqueles que se apresentam no período probatório 
de 03 (três) anos, tempo a ser cumprido até a efetivação. Sugere-se, ainda, a realização de uma nova análise, visando a conhecer a relação entre outros constructos e a questão da confiança nos regimes próprios de previdência complementar.

(Artigo recebido em abril de 2012. Versão final em dezembro de 2012).

\section{Referências bibliográficas}

Agros, Instituto UFV de seguridade social. Histórico 2012. Disponível em: < http:// www.agros.org.br/agros $5 /$ agros $/$ index.php?option $=$ com_content\&view $=$ article\&id=19\&Itemid=27> Acesso em: 10 mai 2012.

.Relatório Anual de Informações 2009. Disponível em:< http:// www.agros.org.br/pdf/rai-2009.pdf> Acesso em: 18 jun 2010.

ARROW, K. J. Uncertainty and the welfare economics of medical care. American Economic Review, n. 53, 1963.

64, p.1-10, 1974.

. Limited Knowledge and Economic Analysis. American Economic Review, v.

. The economics of agency. In: PRATT, J.; ZECKSAUER, R. (editors). Principal and agents: the structure of bussines. Cambridge, MA: Harvard Bussines School Press, 1985. p.37-51.

Barbetta, P.A. Estatística Aplicada às Ciências Sociais. 7. ed. Florianópolis, SC: UFSC, 2008.

Beiguelman, B. Curso Prático de Bioestatística. 4. ed. Rev. Sociedade Brasileira de Genética, Ribeirão Preto, 1996.

Beltrão, K.I.; Oliveira, F. E. B.; Pinheiro, S. S. A População Rural e a Previdência Social no Brasil:uma análise com ênfase nas mudanças constitucionais. (2000). Disponível em: <http://www.ipea.gov.br/pub/td/2000/td_0759.pdf> Acesso em: 25 jun. 2010.

Brasil, Ministério da Previdência Social.Previdência Complementar. Plano do Instituidor. Brasília, DF. Secretaria de Previdência Complementar, 2003.

BYrD, Jonh et al. Stockholder-manager conflits and firm value. Financial Analysts Journal. Charlottesville, v. 54, n. 3, p. 14-30, may/june 1998.

Clegg, S. R.; Hardy, C.; Nord, W. R. Handbook of organization studies. London: Sage Publications, 1996.

Dataprev, Empresa de Tecnologia e Informação da Previdência Social. CNIS (2010). Disponível em: < http://portal.dataprev.gov.br/tag/cnis/> Acesso em: 27 jun. 2010.

Eisenhardt, K. M. Agency theory: an assessment and review. Academy of Management Review, v. 14, n. 1, p.57-74, 1989.

Fukuyama, F. Confiança: as virtudes sociais e a criação da prosperidade. Rocco: Rio de Janeiro, 1996. 
Günther, H. Como elaborar um questionário. (série: Planejamento de Pesquisa nas Ciências Sociais, n 01). Brasília, DF: UNB, Laboratório de Psicologia Ambiental. 2003.

Hair, J.F.; Black, B.; Babbin, B.; Anderson, R.E. Multivariate Data Analysis. 6. ed. Prentice Hall. 2005. 928p.

Натсн, M. J. Organization theory: modern symbolic and postmodern perspectives. New York: Oxford University Press, 1997.

Henriques, C.; Reis, M. Tratamento Estatístico de Dados (2009) Disponível em: <http:// www.estv.ipv.pt/PaginasPessoais/psarabando/CET\%20\%20Ambiente\%202008-2009/ Slides/4.\%20Testes\%20não\%20Paramétricos.pdf> Acesso em: 18 jun. 2010.

Hendriksen, Eldon S.; Breda, Michael F. Van. Teoria da contabilidade. São Paulo: Atlas, 1999.

Holmstrom, B. Moral hazard and observability. Bell Journal of Economics, v. 10, p. 74-91, 1979.

INSS, Instituto Nacional do Seguro Social. Previdência Social: Reflexões e Desafios. 2009. Disponível em: <http://www.inss.gov.br/arquivos/office/3_100202-164641248.pdf> Acesso em: 25 jun. 2010.

Jensen, Michael C.; MeCKuIng, William H. Theory of the firm: managerial behavior, agency costs and ownership structure. Journal of Financial Economics, October 1976. Disponível em: <http://papers.ssrn.com/sol3/delivery.cfm/98060106.pdf?âbstractid=94043>. Acesso em: 27 jun. 2010.

Kluvers, R. Accountability for Perfomance in Local Government. Australian Jornal of Public Administration, v. 62, n. 1, p. 57-69, 2003.

LIMA, M. R. S. Gestão do regime próprio de previdência social: uma investigação sobre o acesso e a compreensão dos servidores frente às informações gerenciais dos municípios do Estado de Pernambuco. 2006. 119p. Dissertação (Mestrado em Ciências Contábeis) - Universidade Federal de Pernambuco, Pernambuco.

Luhmann, N. Trust \& Power. Chichester:Wiley, 1979.

Malhotra, N. K. Pesquisa de marketing: uma orientação aplicada. 3. ed. Porto Alegre: Bookman, 2001.

Mishra, A. K. Organizational responses to crisis: the centrality of trust. In: Kraemer, R.M. e Tyler (eds.). Trust in organizations: frontiers of theory and research. Thousand Oaks, CA: Sage, 1996. p. 261-287.

Mosher, F. Democracy and The Public Service. New York, Oxford University, 1968.

Nakagawa, M. Controladoria e contabilidade no contexto de governança das organizações e da responsabilidade social. 2003. Oficina Governança Corporativa/FEA USP, agosto/2003. Artigo disponível em: <http://www.eac.fea.usp.br/docentes>. Acesso em 26 jun. 2010. Pereira Júnior, Aécio. Evolução histórica da Previdência Social e os direitos fundamentais. Jus Navigandi, Teresina, ano 9, n. 707, 12 jun. 2005. Disponível em: http:/ jus2.uol.com.br/ doutrina/ texto. sp?id=6881 >. Acesso em: 27 jun. 2010.

Prazeres Filho, J.; Viola, D.N.; Lima, V.M.C. Uso do Teste do Aleatorização para Verificar Existência de Correlação Entre Duas Variáveis. 2005. Disponível em: <http:// emr11.de.ufpe.br/cd/trabalhos/T281.pdf> Acesso em: 12 jun. 2010. 
Previdência Social. Anuário Estatístico da Previdência Social. 2008. Disponível em:<http://www.previdencia.gov.br/conteudoDinamico.php?id=850> Acesso em: > 16 jun 2010.

Ribeiro Filho, J. F. Percepções de administradores públicos municipais sobre aspectos da gestão através de resultados. São Paulo. Anteprojeto de Tese de Doutorado em contabilidade e controladoria. FEA/USP, 1999.

SiLva, A. L. H. C. A evolução história da previdência social no Brasil. 2009. Disponível em: <http://www.buscalegis.ccj.ufsc.br/revistas/index.php/buscalegis/article/view/30344/ $29723>$ Acesso em: 23 jun. 2010.

Tiburcio Silva, C.; Tristão, G. Contabilidade básica. 2. ed. São Paulo: Atlas, 2000.

Triola, M.F. Introducão à Estatística . 10. ed. Rio de Janeiro: LTC, 2008.

Tzafrir, S. S.; Harel, G. H. Trust-ME: a scale for measuring manageremployee trustworthiness. Academy of Management. The Academy of Management Review, Mississipi State, Aug. 2002.

UfPe, Universidade Federal de Pernambuco. Testes de Hipóteses não Paramétricos. 2010 Disponível em: <http://www.cin.ufpe.br/ tvrc/arquivos/datamining/ Testes_Nao_Parametricos.pdf $>$ Acesso em: 15 jun 2010.

Zylberstajn, H.; Afonso, L.E.; SouzA, A.P. Reforma da Previdência Social e Custo da Transição: Simulando um Sistema Universal para o Brasil. 2005. Disponível em: <http:// www.anpec.org.br/encontro2005/artigos/A05A052.pdf> Acesso em: 30 jun 2010. 


\section{Resumo - Resumen - Abstract}

\section{Análise da relação principal-agente nos regimes próprios de Previdência Social: o caso do Agros \\ Caio César de Medeiros Costa, Alan Antunes Vieira Macabeu e Marco Aurélio Marques Ferreira}

Este estudo objetivou verificar, sob a ótica dos participantes, os níveis de transparência de gestão administrativa do Instituto Universidade Federal de Viçosa (UFV) de Seguridade Social (Agros) e a confiança nele, além de verificar a relação entre os níveis de transparência e a confiança dos participantes no instituto. Foram coletados dados primários junto aos participantes do Agros, e analisados por meio da análise de frequência e de correlação. Os resultados apontaram que a confiança depende, entre outros aspectos, da formação acadêmica, da frequência no recebimento de informações e da idade dos participantes. Outras variáveis analisadas não se relacionaram de forma significativa. Por meio das análises, torna-se factível afirmar que as variáveis que se relacionam com a confiança, com exceção da frequência no recebimento de informações, são variáveis com as quais o instituto tem pouca influência, limitando o seu poder de ação a curto prazo para modificar questões relacionadas a esse fenômeno. Assim, entre as possíveis ações avaliadas por este estudo, pode-se afirmar que o Agros deve ter um contato constante com os participantes, dando-lhes ciência de suas realizações, buscando um contato frequente e duradouro.

Palavras-chaves: Previdência social; accountability; confiança

\section{Análisis de la relación principal-agente en los regímenes própios de la seguridad social: el caso del Agros \\ Caio César de Medeiros Costa, Alan Antunes Vieira Macaben y Marco Aurélio Marques Ferreira}

Hemos examinado desde la perspectiva de los participantes, los niveles de transparencia en la gestión del Instituto UFV de seguridad social (Agros) y la confianza en el mismo, además de identificar las relaciones entre los niveles de transparencia y la confianza de los participantes en el instituto. Los datos primarios se obtuvieron junto a los participantes del Agros, y se analizaron por medio del análisis de frecuencia y correlación. Los resultados mostraron que la confianza depende, entre otros aspectos, de la formación académica, la frecuencia de recepción de la información y la edad de los participantes. Otras variables no se correlacionaron de manera significativa. Mediante el análisis, se vuelve factible decir que las variables que se relacionan con la confianza, con la excepción de la frecuencia en la recepción de información, son variables con las cuales el instituto tiene poca influencia, lo que limita su poder de acción para modificar las cuestiones del fenómeno a corto plazo. Así, entre las acciones posibles evaluadas en este estudio, se puede afirmar que el Agros debe mantener contacto con los participantes, informándoles sus logros, siempre en búsqueda de un contacto permanente y frecuente.

Palabras-clave: Seguridad social, accountability; confianza

\section{A principal-agent analysis of the social security system: the case of Agros}

Caio César de Medeiros Costa, Alan Antunes Vieira Macabeu and Marco Aurélio Marques Ferreira

This paper aims to verify the levels of transparency in the administration of Agros (Social Security Institute of the Federal University of Viçosa) and the confidence in the Institute by the perspective of the participants. We collected data from a set of participants of the Agros Social Secutiry System. The results showed that confidence depends on the level of schooling, the frequency of receiving information and age of the participants. Excepted for frequency in 
receiving information, variables related to trust are those ones which the Institute has little influence. The Institute should keep in touch with the participants, informing them of its accomplishments.

Keywords: Social security, accountability; trust

\section{Caio César de Medeiros Costa}

Doutorando em Administração Pública e Governo pela Escola de Administração de São Paulo Fundação Getúlio Vargas; mestre em Administração - Universidade Federal de Viçosa. Contato: caiocesq@hotmail.com

Alan Antunes Vieira Macabeu

Mestrando em Administração pela Universidade Federal de Viçosa; bacharel em Direito pela Universidade Federal de Viçosa. Contato: almacabeu@hotmail.com

Marco Aurélio Marques Ferreira

Doutor em Economia Aplicada pela Universidade Federal de Viçosa; professor adjunto do Departamento de Administração e Contabilidade pela Universidade Federal de Viçosa. Contato: marcoaurelio@ufv.br 